LECTURAS DE BIOÉTICA

\title{
La ética de la participación de niños en investigación clínica
}

[The ethics of child participation in clinical research]

Pedro Ernesto Vargas MD., F.A.A.P.

Pediatra y Neunatólogo, Consultorios Médicos Paitilla

Comunicación: Pedro Vargas, Correo electrónico:pedrovargas174@gmail.com,www.pedroevargas.com

Recibido: 18 de febrero de 2021

Publicado: 1 de abril de 2021

Cita: Vargas PE, (2020). La ética de la participación de niños en investigación clínica, 49(3): 101102. DOI: 10.37980/im.journal. rspp.20201745

Palabras clave: ética, investigación clínica, niños

Keywords: ethics, clinical research, children

Reproducción: Artículo de acceso libre para uso personal e individual. Sujeto a derechos de reproducción para otros usos.

Aspectos bioéticos: El autor declara no tener conflictos de interés asociados a la confección de este manuscrito, y no se recibió financiamiento para la confección de este manuscrito.
"Dr. Shirkey" solía decirnos durante nuestra residencia de Pediatría, en la Escuela de Medicina de la Universidad de Tulane, que aquellos que querían mejores medicinas para los niños, debieran incluir, entre sus responsabilidades, la investigación clínica, porque "los niños no eran adultos pequeños", y que era inaceptable que el mercado limitado y más chico en la población pediátrica, dificultara encontrar patrocinio a la investigación en esa población.

Su popular frase de que "los niños son huérfanos terapéuticos" (Therapeutics Orphans) se refería al hecho de que muy poca y pobre investigación en niños, resultaba en el uso de medicamentos para adultos, como único recurso terapéutico. Esto, no permitía conceder ni seguridad ni eficiencia al uso de muchos fármacos en los niños. Por todo esto, no existía la obligación de un etiquetado para las medicinas utilizadas en los niños, como sí existía para las medicinas destinadas a los adultos. Un doble estándar, inaceptable para Dr. Shirkey. Harry era pediatra y farmacólogo, en una época donde contarlos era fácil y desoírlos también era fácil. Él supo cómo hacerse oír. Era un hombre de fácil acceso, bondadoso y de fuertes convicciones.

En bioética contemporánea, el respeto a la persona es el principio prominente, y en el análisis de todo protocolo de investigación, la autonomía es un valor que se prioriza para proteger los derechos del individuo, de grupos y de la comunidad. No tiene por qué ser diferente cuando de niños y adolescentes se trata. Sin embargo, la corta edad de los niños, su vulnerabilidad por ello y su desarrollo que, apenas se inicia, constituyen un obstáculo para respetar su autonomía, que depende de cómo haya transcurrido su niñez y su independencia, inexistente. En la investigación con niños, reconocer y hacer conocer quién se beneficia de ella y quién está expuesto a riesgo, es una obligación moral y ética.

No es difícil descubrir una tensión puntual entre el propósito de que la medicina pediátrica avance y la protección irrestricta del niño frente a su vulnerabilidad. Los niños merecen un cuidado óptimo y la sociedad tiene la obligación moral de darlo. Esa vulnerabilidad es propia de la etapa de la infancia y la niñez, por la que se transcurre cuando se es dependiente para la alimentación, para conservar la salud, para la educación y para el abrigo. El respeto debido a la persona como individuo, dicen Kayte Spector-Bagdady y Jonathan Beever, se le debe también al agregado de individuos, a la comunidad que constituye el interés de la investigación. Entonces, no se trata únicamente de "¿qué es la investigación?", sino también, "¿quién es el sujeto de la investigación?".

La discusión ética se ha movido entre dos corrientes filosóficas representadas por Paul Ramsey, y por Richard McCormick.

Mientras para Ramsey, la investigación en niños que no ofrece un beneficio directo a los participantes y que los utiliza solo como un medio, es inmoral; y sus padres no tienen competencia moral para consentir esa participación, particularmente cuando los exponen a riesgos, pero aún sin exponerlos a riesgo, McCormick rechaza el concepto de que el niño en la investigación sea meramente un medio y, si bien es cierto que tampoco se basa 
su consentimiento a lo que el niño desea o no desea, McCormick enfatiza el rol solidario con la sociedad, que el niño demuestra cuando se le incluye y participa en investigación clínica.

Para otros filósofos, lo inmoral es no llevar a cabo ensayos o investigaciones con niños porque ello obstaculizaría, no solo el avance de la medicina pediátrica, sino también una atención eficaz y segura de patologías que los aquejan e incluso de una medicina preventiva. El niño tiene un lugar en la sociedad, en la comunidad, y su participación en investigaciones no terapéuticas, por ejemplo, es ética y debe ser favorecida.

Para Lainie Friedman Ross, Ramsey desconoce o confunde las obligaciones personales del padre con el niño -que ésta no es una relación fiduciaria- sino que tiene deberes para con su niño y el legítimo derecho de criar a su hijo de acuerdo a sus propios valores e intereses, incluso, que el niño adopte esos valores, y ello significa un balance entre sus necesidades e intereses, la de los padres, la del niño y la de los hermanos del niño. En ese contexto, es moralmente obligante proteger al niño en su vulnerabilidad y esto produce el cuestionamiento válido si entonces el avance de la medicina pediátrica, que es necesario, es apropiado buscarlo con la participación del niño en la investigación clínica.

La respuesta para mí es que la promoción de la participación del niño en la investigación es no solo necesaria sino moralmente válida mientras se asegure una estricta limitación de los riesgos y daños que pudieran producirse, en ensayos diseñados y conducidos de forma impropia. La aprobación de los padres de estos niños para participar en investigación clínica aprobada por comités de ética es también una de probado cumplimiento ético y con su sagrado cumplimiento en la sana crianza de los hijos.

Hoy, al confrontar la pandemia de COVID-19, se produce un quiasma entre la urgente necesidad de atender con eficacia y seguridad la enfermedad para prevenir la muerte y el compromiso jurado de Primum non Nocere. ¿Cuántos niños no son expuestos peligrosamente a medicamentos sin eficacia ni seguridad, calculados a fracciones de dosis, ni siquiera en adultos probadas? ¿Cuánto tendrán que esperar estos niños para ser protegidos con ya probadas vacunas en las poblaciones de jóvenes, adultos y ancianos?

La investigación clínica con las vacunas contra COVID-19 es una necesidad sentida en la población pediátrica, aún conociendo que la enfermedad ha afectado a estas poblaciones de forma diferente que lo ha hecho con los adultos, con o sin co-morbilidades. Es necesario favorecer y promover, como vigilar estrictamente los diseños y la conducción de ensayos con las vacunas para COVID-19 en los niños y cumpliremos los valores de autonomía, justicia, beneficencia y no maledicencia.

\section{Referencias}

1. Doctor Harry Cameron Shirkey, farmacólogo y pediatra

2. Spector-Bagdady K \& Beever J: Retiinking the Importance of the Individual within a Community of Data. Hasting Center Report 50(4): 9-11. July-August, 2020

3. Ramsey P: The Enforcement of Morals: Non-therapeutic Research on Children. Hastings Center Report vol 6(4):21-30. 1976

4. Ramsey P: The patient as Person: Explorations in Medical Ethics. Yale University Press, Hew Haven, CT. 1970

5. McCormick RA: Proxy Consent in the Experimentation Situation. Perspectives in Biology and Medicine. Vol 18(1):2-23. 1974

6. McCormick RA: Experimentation in Children: Sharing in Sociality. Hastings Center Report. Vol 6(6):41-46. 1976 